\title{
Early overnutrition impairs insulin signaling in the heart of adult Swiss mice
}

\author{
Mariana Renovato Martins, Anatalia Kutianski Gonzalez Vieira, Érica Patrícia Garcia de Souza \\ and Anibal Sanchez Moura
}

Department of Physiology, Biology Institute, State University of Rio de Janeiro, Avenue 28 de Setembro, 87-Fundos, $5^{\circ}$ andar, Rio de Janeiro 20550-030, Brazil (Correspondence should be addressed to A S Moura; Email: asmoura@nebin.org)

\begin{abstract}
Human overnutrition has caused a rise in the prevalence of obesity in recent years. In addition to the deleterious effects of obesity during childhood, long-term effects in adulthood have been described as well. For instance, cardiovascular diseases and type 2 diabetes are among the diseases associated with a history of obesity. Altered insulin secretion and action have been described as important links between these diseases and obesity. Insulin acts as a unique anabolic hormone providing regulation of wholebody glucose homeostasis and peripheral tissue glucose uptake in tissues such as the heart. In this study, we examined insulin signaling in the heart of obese animals using an experimental model of inducing overweight adult animals by overnutrition in early life. In these animals, overfeeding during lactation was able to induce a significant increase in body weight starting at the 10th day of life, and this increased weight persisted until
\end{abstract}

adulthood. Impairment in glucose tolerance, hyperinsulinemia, and an increased insulin/glucose ratio were also observed in these animals. Moreover, an increased heart weight/tibia length ratio was also observed, indicating an enlarged heart size. The overfed animals also had decreased insulin sensitivity in the heart, as confirmed by decreased insulin receptor (IR) $-\beta$ and IR substrate-1 (Irs1) phosphorylation, increased phosphatase, non-receptor type 1 (Ptpn1)-IR- $\beta$ association, decreased -Irs1-associated activity, and reduction in anti-phospho Akt1 phosphorylation. In conclusion, our findings showed that overnutrition during early life induced obesity and insulin resistance in the adult offspring, and further increased heart size and impaired cardiac insulin signaling, putatively due to an increase in Ptpn1 activity.

Journal of Endocrinology (2008) 198, 591-598

\section{Introduction}

Recent surveys have shown that more than 1.5 billion people worldwide are thought to be overweight or obese (Deitel 2003, Park et al. 2005, Ogden et al. 2007). Additionally, it has been shown that the obesity epidemic is not confined to a specific period of life, but rather encompasses patients of all ages, including adolescents and children (Ogden et al. 2002, Miller et al. 2004). The great concern regarding childhood obesity is the similarity of symptoms to those observed in adult obesity (Dietz 1994). For instance, risk factors for coronary heart disease (CHD) such as dyslipidemia, hypertension, and impaired glucose tolerance have previously been described in overweight children (Dietz \& Gortmaker 2001). Moreover, it is likely that obesity in early life will cause, among other problems, cardiovascular disease and type 2 diabetes in adulthood (Dietz 1994, Bereson et al. 1998, Weiss et al. 2004, Barker et al. 2007).

The physiological link between these diseases is not yet clear. Nevertheless, it has been suggested that insulin, an anabolic hormone that exerts a multitude of effects on metabolism and various cellular processes in the body
(Watson \& Pessin 2001), may be a key hormone linking the impaired metabolic pathways found in these diseases (Bogardus et al. 1985). Therefore, obesity, cardiovascular disease, and type 2 diabetes have been thought to be the result of a dysfunction in the secretion or action of insulin (Bogardus et al. 1985, Santalucia et al. 1992, Pereira et al. 2006). In addition, the insulin resistance observed in obesity is widely believed to be the first step in the development of cardiovascular diseases (Kolterman et al. 1981, Bogardus et al. 1985, Godfrey \& Barker 2000) and heart failure (Morisco et al. 2006).

During development, insulin acts as a potential mediator between the intrinsic responses to nutritional state, and it coordinates important metabolic actions in almost all body tissues (Shiojima et al. 2002). Glucose uptake, glycogen synthesis, glycolysis, glucose oxidation, and inhibition of fatty acid oxidation are all insulin-dependent processes in various tissues including the cardiac muscle (Carroll et al. 2005). In particular, insulin regulates both glucose uptake and postnatal tissue growth in a peculiar manner in the heart (Weinekove \& Leevers 2000). With regard to energy metabolism in early stages of life, glucose transport in the 
heart occurs in an insulin-independent manner through the insulin-independent glucose transporter SLC2A1 (GLUT1), which is then gradually replaced by the insulin-dependent transporter SLC2A4 (GLUT4), later on in life (Santalucia et al. 1992, Fries et al. 2003). Furthermore, the main source of energy changes from glucose to fatty acids in the adult heart (Lopaschuk et al. 2007). During this developmental process, cellular insulin signaling is an important mechanism for cardiac development. It has been recently described that early-life nutritional changes could induce modifications in cardiac insulin signaling and metabolism (Rutter et al. 2003, Pereira et al. 2006). For instance, obesity exerts strong effects on the heart by inducing high rates of fatty acid oxidation, which in turn results in an inhibition of glucose oxidation (Mazumder et al. 2004, Carroll et al. 2005, Lopaschuk et al. 2007). It is proposed that this mechanism may also contribute to cardiac insulin resistance (Lopaschuk et al. 2007). It has also been demonstrated that cardiomyocytes from $o b / o b$ mice are insulin resistant and show impaired insulin action in the heart (Mazumder et al. 2004).

Experimental studies have suggested that the fetus may be prone to develop obesity and cardiovascular disease in later life when the state of maternal nutrition is altered (Armitage et al. 2005). Moreover, early postnatal overnutrition may represent a risk factor for later obesity and associated metabolic and cardiovascular disturbances in addition to impaired insulin signaling in adipocytes (Rutter et al. 2003, Rodrigues et al. 2007).

In our study, mice raised in small litters to promote the development of obesity into adulthood (Aubert et al. 1980, Plagemann et al. 1992, 1999) were used to study cardiac insulin signaling. Our results showed that animals overfed during lactation later presented obesity, reduction in the insulin signaling pathway in the heart, metabolic disturbances, and diminished peripheral insulin sensitivity.

\section{Materials and Methods}

\section{Animals and treatments}

Virgin female Swiss mice were time crossed at 3 months of age. During pregnancy, they were singly housed under standard conditions. After birth, litters were adjusted to nine pups per dam. At postnatal day 3, the number of pups per dam was adjusted to three male mice per litter to form the overfed group (OG), while the control group (CG) was kept with nine newborn pups per dam. Only male Swiss mice were used in the present study in both the overfed and control groups. After weaning at postnatal day 21, the animals were housed in individual cages with free access to water and standard laboratory chow in a temperature-controlled room with a $12 \mathrm{~h}$ light: $12 \mathrm{~h}$ darkness cycle. The animals were weighed periodically and the daily mean food intake of the animals was measured from 21 to 150 days of age by determining the 24-h consumption of standard pellets. The animals were killed when they reached 20 weeks of age. The animals were cared for in accordance with the Animal Care and Use Committee of the Biology Institute of the State University of Rio de Janeiro, which based its analysis on the principles described in the Guide for Care and Use of Laboratory Animals (Bayne 1996).

\section{I.p. glucose tolerance test (IPGTT)}

An i.p. injection of glucose $(1 \mathrm{~g} / \mathrm{kg}$ body weight) was administrated into $12-\mathrm{h}$ fasted mice at 12 weeks of age. Blood droplets were removed from the tail vein, and blood glucose was measured with a glucometer (ACCU-CHECK Active; Roche Diagnostics $\mathrm{GmbH}$ ) from a $3.5 \mu \mathrm{l}$ sample of tail blood at times -30 (30 min before glucose injection), right before the injection (time 0 ), and at 30,60, and $90 \mathrm{~min}$ following glucose administration.

\section{Visceral fat measurement}

Twenty-week-old male mice were fasted overnight, injected with heparin $(5000 \mathrm{U} / \mathrm{kg})$, and anesthetized with thiopental sodium (40 mg/kg body weight) via i.p. injection. Visceral fat (epididymal fat, retroperitoneal fat, and mesenteric fat) was excised and weighed on an analytical balance.

\section{Blood parameters}

After a 12 -h fast, the 20-week-old overfed and age-matched control mice were anesthetized and killed and their trunk blood was collected to evaluate biochemical parameters. Plasma glucose concentration was determined by the glucose oxidase method (Glucose PP; Diagnostica, Belo Horizonte MG, Brazil), and plasma insulin levels were determined by RIA using specific commercial kit $\left({ }^{125}\right.$ I RIA Kit; MP Biomedicals, Solon, OH, USA). Plasma levels of triglycerides (Triglycerides PP; Diagnostica) and cholesterol (Cholesterol PP; Diagnostica) were determined by enzymatic colorimetric methods.

\section{Estimation of heart size by heart weight/tibia length ratio}

Soon after killing the animals at 150 days of age, their hearts were harvested and weighed on an analytical scale. One leg was removed above the knee joint and the muscle and the skin around the tibias were dissected. The length of the tibias from the condyles to the tip of the medial malleolus was measured by micrometer calipers. The heart size was evaluated by analyzing the heart weight/tibia length ratio (Yin et al. 1982).

\section{Preparation of cardiac muscle}

Soon after harvesting from the killed animals, the hearts were excised and the left ventricles (LVs) were isolated. LVs were then minced and homogenized on ice with a Polytron for $15 \mathrm{~s}$ in a buffer containing $0.3 \mathrm{M}$ HEPES, $0.5 \mathrm{M}$ EDTA, $0.1 \mathrm{M}$ 
sodium fluoride, $1 \mathrm{M}$ sodium pyrophosphate, $0 \cdot 1 \mathrm{mM}$ sodium orthovanadate, $2 \%$ Triton X-100, $10 \mathrm{mg} / \mathrm{ml}$ aprotinin, $5 \mathrm{mg} / \mathrm{ml}$ leupeptin, and $1 \mathrm{mM}$ phenylmethylsulfonyl fluoride. The homogenates were then centrifuged at $400 \mathrm{~g}$ for $15 \mathrm{~min}$ at $4^{\circ} \mathrm{C}$. Pellets were discarded and supernatants frozen at $-20^{\circ} \mathrm{C}$.

\section{Immunoprecipitation}

For immunoprecipitation, homogenized LVs $(0.5 \mathrm{mg}$ of protein) were incubated with polyclonal rabbit anti-insulin receptor (IR) $\beta$ or polyclonal rabbit anti-IR substrate-1 (Irs1) antibodies (1:200; Santa Cruz Biotechnology, Santa Cruz, CA, USA) for $2 \mathrm{~h}$ on ice and gently mixed on a shaker. Next, protein A/G agarose $(20 \mu \mathrm{l} / \mathrm{mg})$ was added and samples were incubated overnight at $4{ }^{\circ} \mathrm{C}$. Immunoprecipitated complexes were collected after centrifugation at $3000 \mathrm{~g}$ for $5 \mathrm{~min}$ at $4{ }^{\circ} \mathrm{C}$, and the supernatant was discarded. Pellets containing the immunoprecipitated complexes were denatured in Laemmli sample buffer (Laemmli 1970). Equal quantities of protein $(20 \mu \mathrm{l})$ were measured and used for western blotting analysis.

\section{Gel electrophoresis and immunoblotting}

The total protein content in the cell extracts was determined by the Bradford method (Bradford 1976). Protein samples were solubilized in Laemmli sample buffer (Laemmli 1970). Equal quantities of protein $(30 \mu \mathrm{l})$ were loaded onto $8 \%$ or $10 \%$ polyacrylamide gel in the presence of SDS, along with pre-stained molecular weight standards (Full Range Rainbow; Amersham Biosciences Ltd). After electrophoretic separation, proteins were transferred to nitrocellulose membranes (Hybond P; Amersham Biosciences Ltd). The membranes were blocked with Tween-TBS (10\% Tween 20) containing $5 \%$ nonfat dry milk for $1 \mathrm{~h}$ and incubated with the appropriate antibodies overnight. The following primary antibodies were used: rabbit anti-Akt1/2 (H-136) Sc-8312 (1:1000; Santa Cruz Biotechnology), rabbit anti-p-Akt1/2/3 (Ser473) Sc-7985-R (1:500; Santa Cruz Biotechnology), rabbit anti-insulin R- $\beta$ (C-19) Sc-711 (1:1000; Santa Cruz Biotechnology), rabbit anti-Irs1 (P-20) Sc-559 (1:1000; Santa Cruz Biotechnology), rabbit anti-PI3K p85 $\alpha$ (Z-8) Sc-423 (1:1000; Santa Cruz Biotechnology), and goat anti-Ptpn1 (N-19) Sc-1718 (1:500; Santa Cruz Biotechnology). To detect the antigen-bound antibody, the blots were incubated with goat anti-rabbit IgG-B Sc-2040 secondary antibody conjugated with biotin for $1 \mathrm{~h}$ (1:10 000; Santa Cruz Biotechnology) and donkey anti-goat IgG-B Sc-2042 (1:5000; Santa Cruz Biotechnology), followed by incubation with streptavidin-horseradish peroxidase conjugate (1:10 000; Zymed, San Francisco, CA, USA) for $1 \mathrm{~h}$. Immunoreactivity was visualized by enhanced chemiluminescence (ECL) using ECL and ECL-Plus (Amersham Biosciences) and subsequently quantified by densitometry using Image J Software (NIH, Bethesda, MD, USA).

\section{Statistical analysis}

Results are expressed as mean \pm s.E.M. Statistical significance was determined by Student's $t$-test for unpaired, bilaterally distributed values of equal variance. $P<0 \cdot 05$ was considered statistically significant.

\section{Results}

\section{Body weight and mean food intake during life}

We measured the body weight of control and overfed male Swiss mice from the day of birth to adulthood $(20$ weeks of age). The animals were weighed periodically, and our data demonstrated that the overfed male mice were clearly overweight when compared with the control group with a significant increase in body weight $\left({ }^{*} P<0 \cdot 05\right)$ at the 10 th day of life. This difference was significant $\left({ }^{*} P<0 \cdot 05\right)$ in all measured ages until 150 days of age (Fig. 1). In addition, daily food intake was measured after the animals were weaned up until 150 days of age. No differences in daily food
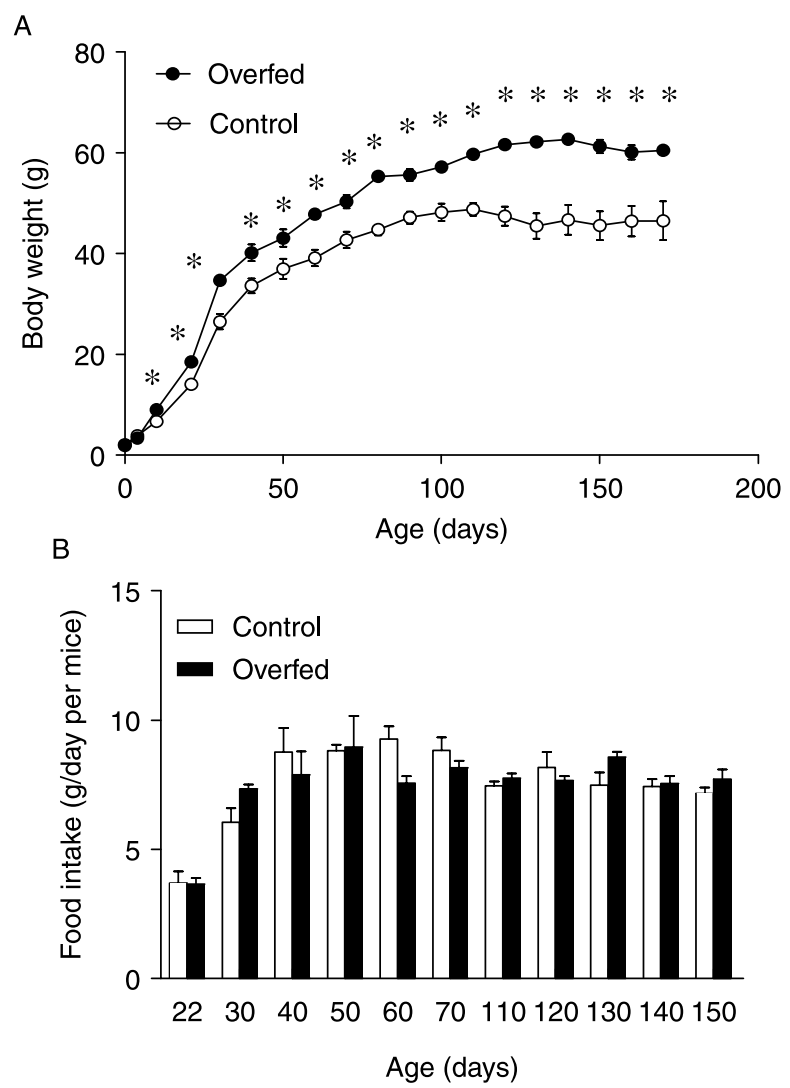

Figure 1 (A) Body weight and (B) mean food intake in overfed and control mice during development. Open and closed symbols represent control and overfed mice respectively. Results are mean \pm S.E.M., $n=9$ animals per group. ${ }^{*} P<0 \cdot 05$, when compared with the control group. 
consumption were observed in the OG during this period when compared with the CG, suggesting that the OG had increased body weight in response to the increased milk availability during the neonatal suckling period.

\section{Glucose tolerance test}

At 120 days of age, a glucose tolerance test was performed in both overfed mice and their age-matched controls. Basal blood glucose concentrations were similar in both control and overfed mice. However, after $30 \mathrm{~min}$ of glucose stimulation, the overfed mice showed an increase in the blood glucose levels compared with that of control mice. After $60 \mathrm{~min}$ of glucose stimulation, the blood glucose level was $47 \%$ higher in the overfed mice compared with the control group. This difference persisted until $90 \mathrm{~min}$ when the blood glucose levels returned to the basal levels in the control group, although the glucose levels were still $57 \%$ higher in the overfed mice (Fig. 2).

\section{Plasma levels of glucose, insulin, triglycerides, and cholesterol}

On the 150th day of life, glucose levels did not differ between the groups (CG: $6.78 \pm 0.73 \mathrm{mmol} / \mathrm{l}, n=10$ vs OG: $6.74 \pm$ $0.45 \mathrm{mmol} / 1, n=10)$. Fasting plasma insulin levels were increased in overfed mice relative to control (CG: 138.39 \pm $15 \cdot 17 \mathrm{pmol} / \mathrm{l}, n=10$ vs OG: $362 \cdot 69 \pm 38 \cdot 48 \mathrm{pmol} / \mathrm{l}, n=10$ ). Insulin/glucose ratio was approximately three times higher in overfed mice compared with controls (CG: 20·82 $\pm 1 \cdot 86, n=10$ vs $\mathrm{OG}: 56 \cdot 54 \pm 8 \cdot 17, n=10)$. Fasting triglyceride and cholesterol levels were similar between the groups (CG: $0 \cdot 41 \pm 0.05 \mathrm{mmol} / 1, \quad n=10$ vs $\mathrm{OG}: 0.49 \pm 0.06 \mathrm{mmol} / \mathrm{l}$, $n=10 ;$ CG: $0.92 \pm 0.07 \mathrm{mmol} / \mathrm{l}, n=10$ vs OG: $1 \cdot 12 \pm$ $0 \cdot 08 \mathrm{mmol} / 1, n=10$; Table 1 ).

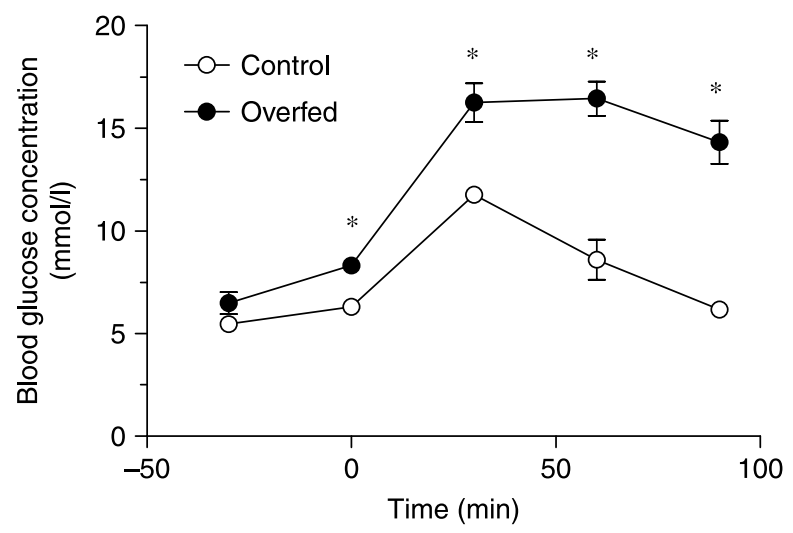

Figure 2 Glucose tolerance test. Blood glucose levels were determined at different time points. Open and closed symbols represent the control and overfed mice respectively. Data are mean \pm S.E.M., $n=6$ animals per group. ${ }^{*} P<0 \cdot 005$ when compared with control group.
Effects of overnutrition during the neonatal suckling period on visceral fat weight and heart size

In accordance with the changes observed in plasma insulin levels and total body weight, visceral fat weight in overfed mice was found to be $59 \%$ higher relative to controls at 150 days of age. Our data also showed that in the OG, the heart weight/tibia length ratios were also increased and that the hearts of overfed mice were $13 \cdot 4 \%$ heavier than those of controls. These results indicated that the hearts of overfed mice were heavier, and therefore bigger, than those of their control counterparts. Moreover, overfed animals presented a clear increase in visceral fat content at 150 days of age (Table 2).

\section{Insulin signaling in the heart}

Finally, to investigate the effects on cardiac insulin signaling resulting from overnutrition during the neonatal suckling period, we examined the basal state phosphorylation of IR- $\beta$, Irs1, and Akt1-Ser473 in the LVs of control and overfed mice. We also investigated protein tyrosine phosphatase, nonreceptor type 1 (Ptpn1) interaction with the IR- $\beta$ after IR- $\beta$ immunoprecipitation. Furthermore, we investigated protein tyrosine Ptpn1 and PI3K interaction with the Irs1 after Irs1 immunoprecipitation.

Overfed animals showed a $32 \cdot 7 \%$ increase in IR- $\beta$ content when compared with controls (Fig. 3A). Interestingly, we found that the OG demonstrated $54 \cdot 8 \%$ less IR- $\beta$ phosphorylation than the CG (Fig. 3B). Furthermore, Ptpn1IR- $\beta$ association was $61 \cdot 8 \%$ higher in overfed animals compared with that of control mice (Fig. 3C).

With regard to Irs 1 content, we did not find any difference between the groups (Fig. 4A). However, overfed animals showed $44 \cdot 5 \%$ less Irs1 phosphorylation when compared with controls (Fig. 4B). Nevertheless, we did not find any difference in Ptpn1-Irs1 association between both groups (Fig. 4C). On the other hand, PI3K-Irs1 interaction was $39 \cdot 6 \%$ lower in overfed groups when compared with controls (Fig. 4D).

We also analyzed Akt1 content as well as its phosphorylation in serine residues. Both the control and the overfed mice had the same Akt1 content in the heart. However, insulin signaling was markedly impaired in the overfed group since these animals presented $38 \cdot 4 \%$ lower Akt1 phosphorylation when compared with control mice (Fig. 5).

\section{Discussion}

The present study demonstrated that the promotion of overfeeding during the neonatal suckling period of mice through a reduction in the litter size induced obesity, visceral fat accumulation, glucose intolerance, hyperinsulinemia, impairment of insulin signaling in the heart under basal conditions, and increased cardiac size. Overnutrition through 
Table 1 Fasting blood parameters. Plasma levels of glucose, triglycerides, cholesterol and insulin, and insulin/glucose ratio. Data are mean \pm S.E.M., $n=10$ animals per group

\begin{tabular}{|c|c|c|c|c|c|}
\hline & Insulin (pmol/l) & Glucose (mmol/l) & Insulin/glucose ratio & Triglycerides $(\mathrm{mmol} / \mathrm{l})$ & Cholesterol $(\mathrm{mmol} / \mathrm{l})$ \\
\hline CG & $138 \cdot 39 \pm 15 \cdot 17$ & $6 \cdot 78 \pm 0 \cdot 73$ & $20 \cdot 82 \pm 1 \cdot 86$ & $0 \cdot 41 \pm 0 \cdot 05$ & $0.92 \pm 0.07$ \\
\hline OG & $362 \cdot 69 \pm 38 \cdot 48^{*}$ & $6 \cdot 74 \pm 0 \cdot 45$ & $56 \cdot 54 \pm 8 \cdot 17^{*}$ & $0.49 \pm 0.06$ & $1 \cdot 12 \pm 0 \cdot 08$ \\
\hline
\end{tabular}

$* P<0 \cdot 0001$ when compared with control group.

litter size reduction is a well-established and suitable experimental model for studying the effects of overnutrition during early adulthood (Aubert et al. 1980, Plagemann et al. 1992, 1999). Early life is considered to be a critical ontogenic window when significant maturation of different organs occurs (Plagemann et al. 1999, Waterland \& Garza 1999). Therefore, nutritional disturbances occurring during this period can lead to the development of persistent effects lasting into adulthood (Bassett \& Craig 1988, Plagemann et al. 1999, Waterland \& Garza 1999, Srinivasan et al. 2006). Furthermore, results from previous studies supported the idea that fetal and/or neonatal nutrition, including nutritional alterations during the lactation period, could modulate the risks of developing adult obesity, diabetes, and cardiovascular diseases (Waterland \& Garza 1999, Srinivasan et al. 2006).

With regard to weight gain, we observed that overfeeding during the neonatal suckling period was able to induce an increase in body weight starting at the 10th day of life, and this effect persisted well into adulthood. Specifically, at 150 days of age, overfed mice were $25 \cdot 6 \%$ heavier than controls. This increase in body weight was accompanied by a $59 \%$ increase in visceral fat accumulation in overfed mice at 150 days of age. However, in contrast to other studies performed in rats (Plagemann et al. 1992, 1999, Rodrigues et al. 2007), which demonstrated that early overnutrition induced persistent hyperphagia, our results showed that overnutrition during the neonatal suckling period did not affect the food intake in overfed mice when compared with control. Therefore, we believe that these increases in body weight and visceral adiposity as observed in the overfed mice were due to the increased availability of milk during neonatal suckling period and its prospective effects on adult energy metabolism.

Findings from several other animal studies suggested a direct relationship among fat accumulation, hyperinsulinemia, and glucose intolerance. For instance, visceral fatderived metabolic products, hormones, and cytokines all play a major role in affecting insulin action in skeletal muscle and in creating a state of low-grade inflammation (Kissebah 1991, Pi-Sunyer 2002, Reaven et al. 2004, Steinberg 2007).

Interestingly, 12-week-old OG were glucose intolerant, hyperinsulinemic, and displayed an increased insulin/glucose ratio, all signs indicative of peripheral insulin resistance. Although overfed mice were hyperinsulinemic, there was no increase in the fasting plasma levels of glucose, triglycerides, or cholesterol. The normoglycemic profile found in overfed animals was probably maintained by a compensatory increase in circulating insulin levels. The same metabolic process was observed in Zucker diabetic fatty rats. These rats clearly displayed peripheral insulin resistance but maintained normal glucose levels through a compensatory elevation in circulating insulin (Pi-Sunyer 2002). Hyperinsulinemia is known to inhibit lipolysis and free fatty acid (FFA) release from the adipocytes (Ilany et al. 2006). Conversely, it can stimulate FFA storage and, consequently, triglyceride accumulation in various tissues including the adipose tissues (Ilany et al. 2006, Morisco et al. 2006). Since fat accumulation was increased in overfed mice, we concluded that the observed increase in intracellular accumulation of triglycerides was likely the cause for why these mice maintained unaltered plasma triglyceride levels. However, further studies are necessary to elucidate the mechanisms responsible for the weight gain in these animals. The effects of hyperinsulinemia in adipose tissues, which include inhibition of lipolysis and stimulation of lipogenesis, are probably the main reason why overfed animals became overweight when compared with their control counterparts, even though both groups of animals ate the same daily quantity of food.

Obesity and hyperinsulinemia are the major causes of heart diseases. For instance, hyperinsulinemia has been associated with an increased risk of CHD, and fasting insulin levels have been correlated directly with increased mortality due to CHD. In the Paris Prospective Study, which evaluated CHD risk factors in more than 7000 working men, fasting insulin

Table 2 Body weight, body length, visceral fat weight, heart weight, tibial length, and HW/TL ratio at 20 weeks of age. Effects of overnutrition during the neonatal suckling period on visceral fat weight in overfed and control mice and estimation of the cardiac size by calculating the heart weight/tibia length ratios (HW/TL). Data are mean \pm S.E.M., $n=9$ animals per group

\begin{tabular}{|c|c|c|c|c|c|}
\hline Body weight (g) & Nasoanal body length $(\mathrm{cm})$ & Visceral fat weight (g) & Heart weight $(\mathrm{g})$ & Tibial length $(\mathrm{cm})$ & $\mathrm{HW} / \mathrm{TL}$ ratio \\
\hline $50 \cdot 4 \pm 1 \cdot 22$ & $10 \cdot 2 \pm 0 \cdot 10$ & $0 \cdot 85 \pm 0 \cdot 08$ & $0 \cdot 19 \pm 0 \cdot 002$ & $2 \cdot 09 \pm 0 \cdot 01$ & $0 \cdot 09 \pm 0 \cdot 001$ \\
\hline $64 \cdot 5 \pm 1 \cdot 00^{*}$ & $10 \cdot 5 \pm 0 \cdot 08$ & $2 \cdot 07 \pm 0 \cdot 13^{*}$ & $0 \cdot 23 \pm 0 \cdot 007^{*}$ & $2 \cdot 12 \pm 0 \cdot 01$ & $0 \cdot 10 \pm 0 \cdot 003 *$ \\
\hline
\end{tabular}

$* P<0 \cdot 005$ when compared with the control group. 


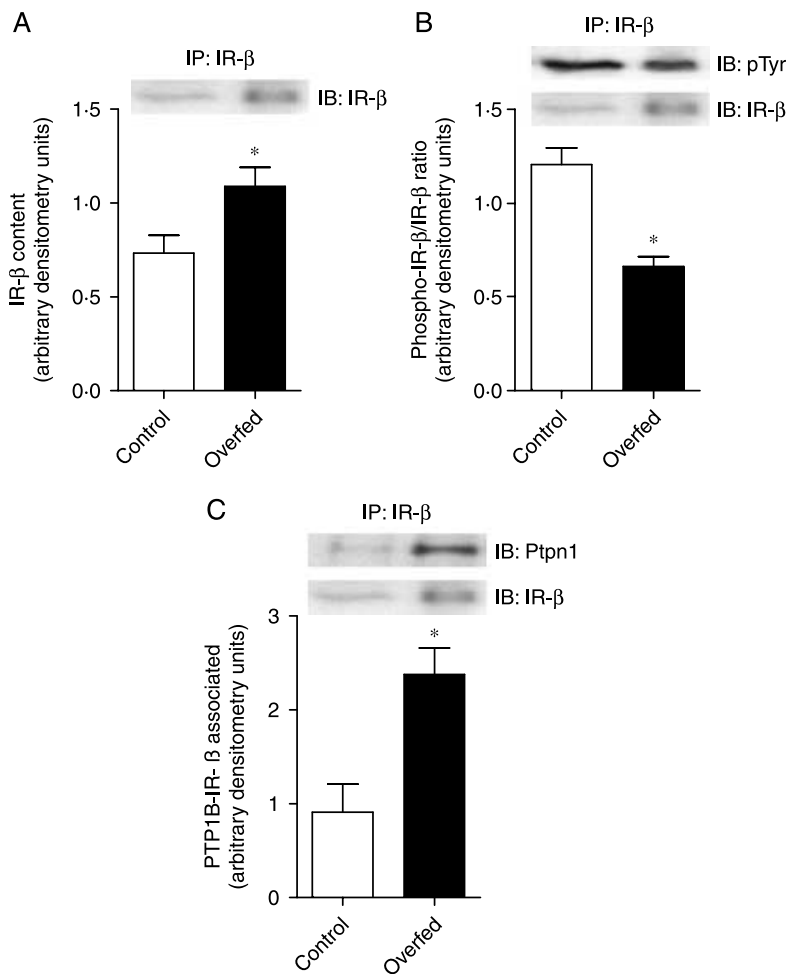

Figure 3 Western blot analyses of (A) insulin receptor (IR) content, (B) IR phosphorylation, and (C) Ptpn1-IR- $\beta$ association after immunoprecipitation in left ventricles of control and overfed mice. Open and closed bars represent controls and overfed mice respectively. Data are mean \pm S.E.M., $n=6$ animals per group. $* P<0 \cdot 05$ when compared with control group.

levels were found to be an independent predictor of CHD death. Similarly, fasting insulin levels were also found to be an independent risk factor for developing CHD in a case-control study of Canadian men (Pi-Sunyer 2002). Moreover, several studies have reported a direct correlation between insulin resistance and left ventricular mass with significant ventricular hypertrophy in insulin-resistant patients (Rutter et al. 2003).

In the present study, we evaluated for possible cardiac alterations in mice raised in small litters by analyzing the heart weight/tibia length ratio and cardiac insulin signaling. Consistent with the literature, adult overfed mice presented increased heart weight/tibia length ratio, which is an indication of increased cardiac size. Moreover, overfed animals had decreased insulin sensitivity in the heart (as confirmed by decreased IR- $\beta$ and Irs1 phosphorylation), increased Ptpn1-IR- $\beta$ association, decreased Irs1-PI3K interaction, and decreased Akt1 phosphorylation.

It is known that cardiac insulin resistance might be an adaptive event during the progression of obesity-associated diabetes via increased lipid flux into cardiomyocytes and a compensatory decrease in glucose metabolism (Reaven et al. 2004, Park et al. 2005). As expected, cardiac insulin signaling
A
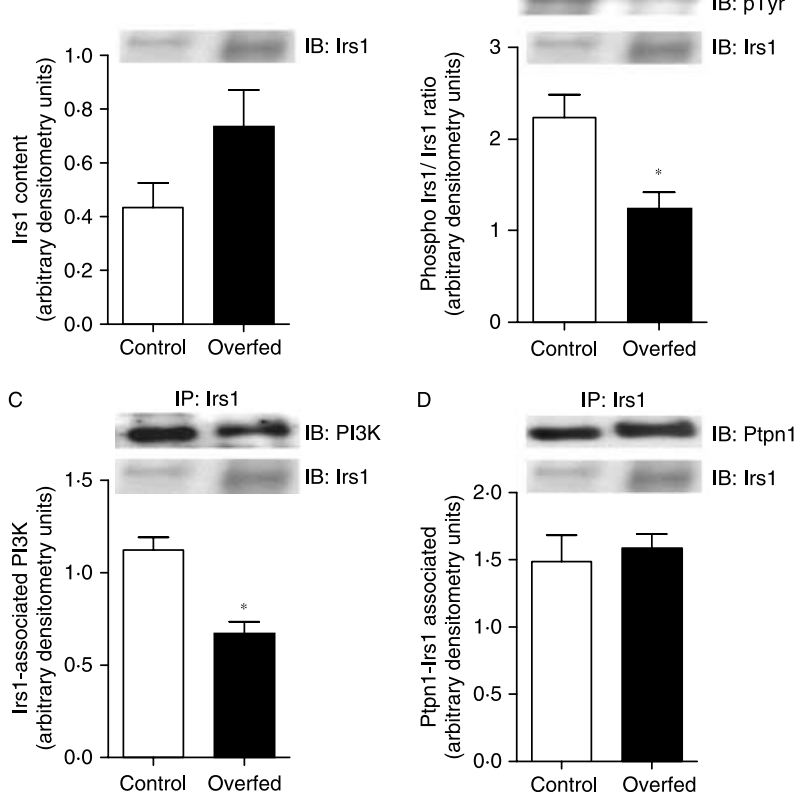

Figure 4 Western blot analyses of (A) insulin receptor substrate (Irs1) content, (B) insulin receptor substrate tyrosine phosphorylation (phospho-Irs1), (C) Irsl-associated Ptpn1, and (D) Irs1associated PI3K after immunoprecipitation in left ventricles of control and overfed mice. Open and closed bars represent controls and overfed mice respectively. Data are mean \pm s.E.M., $n=5$ animals per group. ${ }^{*} P<0.05$ when compared with control group.

was impaired in overfed animals. Despite decreased IR- $\beta$ phosphorylation in the overfed mice, IR- $\beta$ content was actually enhanced in this group. We suggested that it may be a compensatory mechanism to prevent insulin resistance in the heart. However, this adaptation was found to be inefficient to maintain normal IR phosphorylation in tyrosine (Tyr)

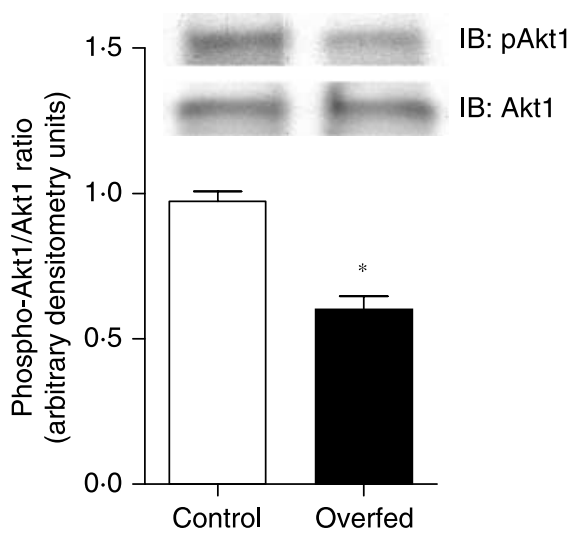

Figure 5 Western blot analyses of Akt1 (Ser) phosphorylation in left ventricles of control and overfed mice. Open and closed bars represent controls and overfed mice respectively. Data are mean \pm S.E.M., $n=6$ animals per group. ${ }^{*} P<0.05$ when compared with control group. 
residues. One possible explanation for the decreased insulin Tyr phosphorylation is the increased Ptpn1-IR- $\beta$ association in overfed mice, since the enzyme Ptpn1 modulates the insulin pathway by dephosphorylating phosphotyrosine residues on the IR (Asante-Appiah \& Kennedy 2003).

With regard to Irs1 content, we did not find any difference between overfed and control mice. However, overfed mice displayed decreased Irs1 tyrosine phosphorylation compared with controls. With Ptpn1-Irs1 association, there was no difference when both groups were compared. Moreover, the suppressed Irs1 tyrosine phosphorylation found in overfed animals was not in response to increased Ptpn1-Irs1 association, and this may be occurring due to serine phosphorylation of Irs1 (Steinberg 2007).

Consequently, augmented IR- $\beta$ tyrosine dephosphorylation by protein tyrosine phosphatases may contribute to insulin resistance (Calera et al. 2000, Asante-Appiah \& Kennedy 2003, Nieto-Vazquez et al. 2007). Thus, the regulation of IR tyrosine phosphorylation is a key step in controlling insulin signaling. It is likely that the increase in Ptpn1 in the heart of overfed mice led to impaired IR phosphorylation in this tissue. Hence, our findings confirmed the importance of Ptpn1 as a negative regulator of insulin signaling in the heart.

In addition to the decreased tyrosine phosphorylation on the Irs1, the overfed animals also showed decreased PI3K-Irs1 interaction. This was an important finding since PI3K activates the phosphoinositide-dependent protein kinase that go on to phosphorylate Akt1 (Watson \& Pessin 2001).

The level of Akt1 serine phosphorylation was found to be diminished in overfed animals. These data are consistent with a picture of impaired IR- $\beta$ and Irs1 phosphorylation and PI3K activation, since Akt1 is a downstream molecule to IR- $\beta$, Irs1, and PI3K in the insulin signaling pathway (Watson \& Pessin 2001). Accordingly, this reduction in Akt1 phosphorylation can impair cardiac glucose metabolism, since Akt1 activation is necessary for Slc2a4 (solute carrier family 2 (facilitated glucose transporter), member 4) translocation from the intracellular compartments to the cell surface, thereby allowing an adequate level of glucose uptake (Saltiel \& Kahn 2001, Morisco et al. 2006). In addition, previous studies have indicated that decreased serine phosphorylation Akt1 (Ser473) is correlated with insulin resistance (Berg et al. 2002, Nikolaidis et al. 2004).

In conclusion, our study demonstrated that overfeeding during the neonatal suckling period through litter size reduction is a suitable model for studying the effects of early nutritional disturbances on cardiac and metabolic changes in adulthood. Our data strongly suggests that overfeeding during the neonatal suckling period induces the development of obesity and insulin resistance in the adult mice, with concomitant increase in cardiac size and impairment of cardiac insulin signaling caused by an increase in Ptpn1-IR- $\beta$, decreased Irs1 phosphorylation, and decreased PI3K-Irs1associated activity.

\section{Declaration of Interest}

This work has no conflict of interest that would prejudice its impartiality.

\section{Funding}

This work was financially supported by CAPES (Coordenação de Aperfeiçoamento de Pessoal de Nível Superior), CNPq (Conselho Nacional de Desenvolvimento Científico e Tecnológico), and FAPERJ (Fundação de Apoio à Pesquisa do Estado do Rio de Janeiro).

\section{Acknowledgements}

We especially thank Renata Oliveira Pereira for her critical reading of the manuscript.

\section{References}

Armitage JA, Taylor PD \& Poston L 2005 Experimental models of developmental programming: consequences of exposure to an energy rich diet during development. Journal of Physiology 565 3-8.

Asante-Appiah E \& Kennedy BP 2003 Protein tyrosine phosphatases: the quest for negative regulators of insulin action. American Journal of Physiology. Endocrinology and Metabolism 284 E663-E670.

Aubert R, Suquet JP \& Lemmonier D 1980 Long-term morphological and metabolic effects of early under over-nutrition in mice. Journal of Nutrition 110 649-661.

Barker JL, Olsen LW \& Sorensen TIA 2007 Childhood body-mass index and the risk of coronary heart disease in adulthood. New England Journal of Medicine 357 3329-3337.

Bassett DR \& Craig BW 1988 Influence of early nutrition on growth and adipose tissue characteristics in male and female rats. Journal of Applied Physiology 64 1249-1256.

Bayne K 1996 Revised guide for the care and use of laboratory animals available. American Physiological Society. Physiologist 39 208-211.

Bereson GS, Srinivasan SR, Bao W, Newman WP III, Tracy RE \& Wattigney WA 1998 Association between multiple cardiovascular risk factors and atheroschlerosis in children: a prospective study. New England Journal of Medicine 338 1650-1656.

Berg CE, Lavan BE \& Rondinone CM 2002 Rapamycin partially prevents insulin resistance induced by chronic insulin treatment. Biochemical and Biophysical Research Communications 293 1021-1027.

Bogardus C, Lillioja S, Mott DM, Hollenbeck C \& Reaven G 1985 Relationship between degree of obesity and in vivo insulin action in man. American Journal of Physiology 248 E286-E291.

Bradford MM 1976 A rapid and sensitive method for the quantitation of microgram quantities of protein utilizing the principle of protein-dye binding. Analytical Biochemistry 72 148-254.

Calera MR, Vallega G \& Pilch PF 2000 Dynamics of protein-tyrosine phosphatases in rat adipocytes. Journal of Biological Chemistry 275 6308-6312.

Carroll AR, Carley AN, Dyck JR \& Severson DL 2005 Metabolic effects of insulin on cardiomyocytes from control and diabetic $\mathrm{db} / \mathrm{db}$ mouse hearts. American Journal of Physiology. Endocrinology and Metabolism 288 E900-E906.

Deitel M 2003 Overweight and obesity worldwide now estimated to involve 1.7 billion people. Obesity Surgery 13 329-330.

Dietz WH 1994 Critical periods in childhood for the development of obesity. American Journal of Clinical Nutrition 59 955-959.

Dietz WH \& Gortmaker SL 2001 Preventing obesity in children and adolescents. Annual Review of Public Health 22 337-353.

Fries I, Cao-Dahn H, Stamm C, Cowan DB, McGowan FX \& del Nido PJ 2003 Postnatal increase in insulin-sensitive glucose transporter expression is associated with improved recovery of postischemic myocardial function. Journal of Thoracic and Cardiovascular Surgery 126 236-271. 
Godfrey MK \& Barker DJ 2000 Fetal nutrition and adult disease. American Journal of Clinical Nutrition 71 (Suppl 5) 1344S-1352S.

Ilany J, Bilan PJ, Kapur S, Caldwell JS, Patty ME, Marette A \& Kahn CR 2006 Overexpression of $\mathrm{Rad}$ in muscle worsens diet-induced insulin resistance and glucose intolerance and lowers plasma triglyceride level. PNAS 103 4481-4486.

Kissebah AH 1991 Insulin resistance in visceral obesity. International Journal of Obesity 15 (Suppl 2) 109-115.

Kolterman OG, Gray RS, Griffin J, Burstein P, Insel J, Scarlett JA \& Olefsky JM 1981 Receptor and postreceptor defects contribute to the insulin resistance in noninsulin-dependent diabetes mellitus. Journal of Clinical Investigation 68 957-969.

Laemmli UK 1970 Cleavage of structural proteins during the assembly of the head of bacteriophage T4. Nature 227 680-685.

Lopaschuk GD, Folmes CD \& Stanley WC 2007 Cardiac energy metabolism in obesity. Circulation Research 101 335-347.

Mazumder PK, O’Neill BT, Roberts MW, Buchanan J, Yun UJ, Cooksey RC, Boudina S \& Abel ED 2004 Impaired cardiac efficiency and increased fatty acid oxidation in insulin-resistant ob/ob mouse hearts. Diabetes 53 2366-2374.

Miller J, Rosenbloom A \& Silverstein J 2004 Childhood obesity. Journal of Clinical Endocrinology and Metabolism 89 4211-4218.

Morisco C, Lembo G \& Trimarco B 2006 Insulin resistance and cardivascular risk: new insights from molecular and cellular biology. Tiends in Cardiovascular Medicine 16 183-188.

Nieto-Vazquez I, Fernández-Veledo S, de Álvaro C, Rondinone CM, Valverde AM \& Lorenzo M 2007 Protein-tyrosine phosphatase 1Bdeficient myocytes show increased insulin sensitivity and protection against tumor necrosis factor- $\alpha$-induced insulin resistance. Diabetes 56 404-413.

Nikolaidis LA, Sturzu A, Stolarski C, Elahi D, Shen YT \& Shannon RP 2004 The development of myocardial insulin resistance in conscious dogs with advanced dilated cardiomyopathy. Cardiovascular Research 61 297-306.

Ogden CL, Flegal KM, Carroll MD \& Johnson CL 2002 Prevalence and trends in overweight among US children and adolescents, 1999-2000. Journal of the American Medical Association 288 1728-1732.

Ogden CL, Yanovsky SZ, Carrol MD \& Flegal KM 2007 The epidemiology of obesity. Gastroenterology 132 2087-2102.

Park SY, Cho IR, Kim HJ, Higashimori T, Danton C, Lee MK, Dey A, Rothermel B, Kim YB, Kalinowski A et al. 2005 Unraveling the temporal pattern of diet-induced insulin resistance in individual organs and cardiac dysfunction in C57BL/6 mice. Diabetes 54 3530-3540.

Pereira RO, Moreira ASB, de Carvalho L \& Moura AS 2006 Overfeeding during lactation modifies insulin and leptin cascade in rat's hearts. Regulatory Peptides 136 117-121.

Pi-Sunyer FX 2002 The obesity epidemic: pathophysiology and consequences of obesity. Obesity Research 10 (Suppl 2) 97S-104S.

Plagemann A, Heidrich I, Götz F, Rohde W \& Döner G 1992 Obesity and enhanced diabetes and cardiovascular risk in adult rats due to early postnatal overfeeding. Experimental and Clinical Endocrinology 99 154-158.

Plagemann A, Harder T, Rake A, Voits M, Fink H, Rohde W \& Dörner G 1999 Perinatal elevation of hypothalamic insulin, acquired malformation of hypothalamic galaninergic neurons, and syndrome X-like alterations in adulthood of nenonatally ovefed rats. Brain Research 836 146-155.
Reaven G, Abbasi F \& McLaughlin T 2004 Obesity, insulin resistance and cardiovascular disease. Recent Progress in Hormone Research 59 207-223.

Rodrigues AL, De Souza EP, Da Silva SV, Rodrigues DS, Nascimto AB, Barja-Fidalgo C \& DeFreitas MS 2007 Low expression of insulin signaling molecules impairs glucose uptake in adipocytes after early overnutriton. Journal of Endocrinology 195 485-494.

Rutter MK, Parise H, Benjamin EJ, Levy D, Larson MG, Meigs JB, Nesto RW, Wilson PW \& Vasan RS 2003 Impact of glucose intolerance and insulin resistance on cardiac structure and function: sex-related differences in the Framingham Heart Study. Circulation 107 448-454.

Saltiel AR \& Kahn CR 2001 Insulin signalling and the regulation of glucose and lipid metabolism. Nature $\mathbf{4 1 4}$ 799-806.

Santalucia T, Camps M, Castelló A, Muñoz P, Nuel A, Testar X, Palacín M \& Zorzano A 1992 Developmental regulation of GLUT-1 (erythroid/Hep G2) and GLUT-4 (muscle/fat) glucose transporter expression in rat heart, skeletal muscle, and brown adipose tisssue. Endocrinology 130 837-846.

Shiojima I, Yefremashvili M, Lou Z, Kureishi Y, Tkahashi A, Tao J, Rosenzweig A, Kahn R, Abel D \& Walsh K 2002 Akt signaling mediates post-natal heart growth in response to insulin and nutritional status. Journal of Biological Chemistry 40 37670-37677.

Srinivasan M, Aalinkeel R, Song F, Mitrani P, Pandya JD, Strutt B, Hill DJ \& Patel MS 2006 Maternal hyperinsulinemia predisposes rat fetuses for hyperinsulinemia, and adult-onset obesity and maternal mild food restriction reverses this phenotype. American Journal of Physiology. Endocrinology and Metabolism 290 E129-E134.

Steinberg GR 2007 Inflammation in obesity is the common link between defects in fatty acid metabolism and insulin resistance. Cell Cycle 6 888-894.

Waterland RA \& Garza C 1999 Potential mechanisms of metabolic imprinting that lead to chronic disease. American Journal of Clinical Nutrition 69 179-197.

Watson RT \& Pessin JE 2001 Intracellular organization of insulin signaling and GLUT-4 translocation. Recent Progress in Hormone Research 56 175-193.

Weinekove D \& Leevers SJ 2000 The genetic control of organ growth: insights from Drosophila. Current Opinion in Genetics \& Development 10 75-80.

Weiss R, Dziura J, Burger TS, Tamborlane WV, Takasali SE, Yeckel CW, Allen K, Lopes M, Savoye M, Morrison J et al. 2004 Obesity and metabolic syndrome in children and adolescents. New England Journal of Medicine 359 2363-2374.

Yin FCP, Spurgeon HA, Rakusan K, Weisfeldt M \& Lakatta EG 1982 Use of tibial lenght to quantify cardiac hypertophy: application in the aging rat. American Journal of Physiology 246 H941-H947.

Received in final form 29 June 2008

Accepted 3 July 2008

Made available online as an Accepted Preprint

3 July 2008 